\title{
O trabalho improdutivo e suas configurações no século $X X$
}

Unproductive labor and its configurations in the twentieth century

\author{
Fernando de Araújo Bizerra* \\ Juliana Carla da Silva Gois** \\ Manuella Aragão Pinheiro***
}

\begin{abstract}
Resumo - Tendo em vista que nas últimas décadas o sistema do capital vem vivenciando uma crise sem precedentes que, por sua vez, como consequência direta, provoca alterações nas relações de produção, recoloca-se, sem dúvida, a necessidade de se continuar refletindo sobre as questões que permeiam a categoria trabalho. Neste artigo, em particular, tem-se o propósito de abordar as configurações assumidas historicamente pelo trabalho improdutivo na dinâmica expansionista do capital no século XX. Apreende-se, num primeiro momento, que as atividades monótonas e repetitivas típicas do padrão tayloristafordista foram possíveis graças à gerência científica exercida pelos trabalhadores improdutivos. Seguidamente, demonstra-se que, ao se expandir por diversos setores, conjugando-se com as exigências da fábrica toyotista, essa forma de trabalho assume contornos específicos. Esses, dentre outros, são os aspectos que compõem o presente estudo. Palavras-chave: trabalho produtivo; trabalho improdutivo; divisão social do trabalho; setor de serviços.
\end{abstract}

\begin{abstract}
In recent decades the capital system has been experiencing an unprecedented crisis which, in turn, has been changing the relations of production as a direct consequence. This development undoubtedly raises again the need of continual reflection regarding the "labor" category. This particular article addresses the historical configurations of unproductive labor in the unrestrained, expansionist dynamics of capital in the twentieth century. At first, it is shown that the typical
\end{abstract}

\footnotetext{
* Assistente Social, Mestre pelo Programa de Pós-Graduação em Serviço Social (PPGSS) da Universidade Federal de Alagoas (UFAL). Professor Assistente do Curso de Serviço Social da UFAL - Campus Arapiraca/Unidade Educacional de Palmeira dos Índios. Membro do Grupo de Pesquisa sobre Reprodução Social. Correspondência: Rua Bela Vista, 699, Brasília, Arapiraca/AL. CEP: 57313-180. Email: <nando_epial@hotmail.com>.

** Assistente Social, Mestre pelo Programa de Pós-Graduação em Serviço Social (PPGSS) da Universidade Federal de Alagoas (UFAL) e Doutoranda pelo Programa de Pós-Graduação da Universidade Federal do Rio Grande do Norte (UFRN). Assistente social do Campus Arapiraca do Instituto Federal de Alagoas (IFAL). Membro do Grupo de Pesquisa Mercado de Trabalho do Serviço Social. Correspondência: Rua Carlos Cesar Araújo, 60, Baixa Grande, CEP: 57307-190. Email: <juh-carla@hotmail.com>.

*** Assistente Social, Mestre pelo Programa de Pós-Graduação em Serviço Social (PPGSS) da Universidade Federal de Alagoas (UFAL). Assistente social do Campus A. C. Simões da Universidade Federal de Alagoas (UFAL). Membro do Grupo de Pesquisa sobre Reprodução Social. Correspondência: Avenida Professor Vital Barbosa, edf. Ocean Ville, 616, apto. 603, Ponta Verde, Maceió/AL. CEP: 57035-400.Email: <manuella_aragao@hotmail.com>.
} 
monotonous and repetitive activities of the Taylorist and Fordist models were possible thanks to scientific management exercised by unproductive workers. Next, it is demonstrates that this type of labor has specific features, by spanning various sectors and combining it with the requirements of the Toyotist factory. These, among others, are the aspects that make up this study.

Keywords: productive labor; unproductive labor; social division of labor; service sector.

\section{Introdução}

Desde a segunda metade do século XX, numa delimitação histórica mais precisa, assiste-se a uma verdadeira epidemia de teorias que promulgam o fim da centralidade do trabalho no mundo dos homens e, no aspecto sociopolítico, o "adeus ao proletariado". Os argumentos, por vezes, são os mais variados. Sustenta-se - como é o caso de Schaff, Lojkine, Bell, Toffler, embora com diferenças - a afirmação de que o incremento pujante das tecnologias computadorizadas na produção, como a automação e a informatização, ao ampliar as possibilidades de difusão do conhecimento, constituem o anúncio e a potencialidade de uma nova civilização, nitidamente pós-mercantil, mais justa e igualitária. Sendo, assim, totalmente diferente da industrial: a "sociedade de informação".

Por meio dela, a humanidade seria levada, aos poucos, a um novo patamar organizacional situado para além do capitalismo, pois

A sociedade de informação, segundo seus teóricos, gera mudanças no nível mais fundamental da sociedade. Inicia um novo modo de produção. Muda a própria fonte da criação de riqueza e os fatores determinantes da produção. O trabalho e o capital, as variáveis básicas da sociedade industrial, são substituídas pela informação e pelo conhecimento. A teoria do valor do trabalho, da maneira formulada por uma sucessão de pensadores clássicos, de Locke e Smith a Ricardo e Marx, é obrigada a ceder lugar a uma 'teoria do valor do conhecimento, e não do trabalho, e a origem do valor'. (KUMAR, 2006, p. 24).

Alega-se, ainda, que a produção flexível típica das fábricas enxutas toyotistas e a expansão do setor de serviços provocaram mudanças que, ao serem positivas para quem labuta diariamente, deixaram para trás o trabalho tedioso, ingente e monótono que implica a desqualificação dos operários, abrindo espaço para a requalificação do trabalho, para a fusão entre o trabalho manual e o intelectual e, por que não, o produtivo e o improdutivo. Os antagonismos que balizam a divisão do trabalho tipicamente capitalista estariam, por definitivo, sendo superados.

Em se tratando das categorias trabalho produtivo e improdutivo, desde os fisiocratas, passando por Smith, Marx, até autores contemporâneos como Mandel, Rubin, Napoleoni e outros, as polêmicas em torno delas fo- 


\section{ADVistg all pavtg}

\} O TRABALHO IMPRODUTIVO E SUAS CONFIGURAÇÕES - BIZERRA, F. A. ; GOIS, J. C. S. ; PINHEIRO, M. A. \}

DOI: $10.12957 /$ REP.2016.25391

ram se construindo. Abre-se nitidamente uma linha divisória de análises saturadas de dissonâncias. Como bem constata Dal Rosso (2014), não existe, na literatura produzida, uma leitura inteiramente consensual; ao contrário, ela é, segundo o autor, "de natureza inteiramente diversa". No entanto, embora reconheçamos esse fato de grande importância, não é sobre ele que nos debruçaremos aqui.

Este artigo não se volta para o debate teórico instaurado nas Ciências Sociais sobre o trabalho produtivo e improdutivo. Versa, pois, sobre o trabalho improdutivo na dinâmica autoexpansiva do capital no século XX. Pretende-se demonstrar que essa forma de trabalho assume configurações distintas e funções peculiares correspondentes a cada conjuntura, comprovando, assim, que o aumento de atividades improdutivas dentro e fora do espaço fabril responde às determinações e exigências mais imperativas do modo de produção capitalista.

Parte-se da premissa de que o trabalho abstrato, típico do capitalismo, materializa-se, para atender a diferentes necessidades, em trabalho produtivo e improdutivo. Ambos são funcionais, necessários e imprescindíveis à reprodução ampliada do capital, mas distintos ontologicamente: a esfera produtiva produz mais-valia e a esfera improdutiva não a produz. Se se considerar que a finalidade última da produção capitalista é, em todo caso, a obtenção da mais-valia produzida pela exploração do trabalhador, logo, aparentemente (mas, só aparentemente), seria um "paradoxo" a existência de um trabalho que, por estar submetido às exigências do sistema, não a produza. Pautando-se na análise histórica e crítica da realidade, o intuito é justamente o de contribuir para o desvelamento desse suposto "paradoxo" a partir da demonstração da coexistência necessária entre trabalho produtivo e improdutivo.

\section{Trabalho produtivo e trabalho improdutivo: breves diferenças ontológicas}

Marx (1983), em O capital, evidencia que é a partir do trabalho que se produz o novo que impulsiona a humanidade a patamares sempre mais elevados de sociabilidade. Mas o que o especifica? Para responder corretamente a tal indagação, vale a pena recorrer ao Capítulo $\vee$ da referida obra, onde se lê:

[...] o trabalho é um processo entre o homem e a Natureza, um processo em que o homem, por sua própria ação, media, regula e controla seu metabolismo com a Natureza. Ele mesmo se defronta com a matéria natural como uma força natural. Ele põe em movimento as forças naturais pertencentes a sua corporalidade, braços e pernas, cabeça e mão, a fim de apropriar-se da matéria natural numa forma útil para sua própria vida. (MARX, 1983, p. 297). 
O trabalho é o processo de transformação da natureza mediada pela ação consciente do homem sobre a mesma. O homem - pertencente a uma organização social especificamente constituída - transforma a materialidade natural, externa a ele, em algo necessário à sua subsistência. Exercendo o controle sobre a natureza, o homem sujeita as forças físicas e mentais do seu corpo para produzir, "numa forma útil" e sempre de maneira nova, coisas que atendam às necessidades relacionadas à sua autopreservação: comer, beber, vestir-se, habitar.

A natureza constitui a base insuprimível da vida em sociedade, pois não se pode, em hipótese alguma, haver a reprodução social sem a transformação daquela nos meios de produção e subsistência imprescindíveis a cada sociabilidade. Ou, dito de outra forma, a sociedade, quer na sua forma mais primitiva, quer na sua expressão mais complexa, é impossível sem a natureza. Essa impossibilidade de existência da sociedade sem a natureza resulta na dependência da primeira em relação à segunda. Não há vida social sem a natureza.

Todavia, o inverso não é verdadeiro: a natureza existe independentemente da sociedade, é algo a ela anterior. Vale ressaltar que isso deve ser corretamente compreendido para não se cair em deformações que entendem ser o funcionamento da sociedade sujeito às mesmas leis que operam na objetividade natural. Quando ocorre essa transposição simplista, desconsidera-se que a peculiaridade da vida em sociedade consiste no fato de que ela é edificada pela ação consciente dos homens ao encontrarem cada vez menos prontas as condições para sua reprodução, produzindoas, através do trabalho, sob pena de fenecerem.

Cabe sublinhar, já que por vezes isso tende a ser negligenciado, que tal constatação é válida também para a sociedade capitalista, pois sem o intercâmbio orgânico com a natureza o capital, enquanto riqueza produzida pela exploração do trabalho, não pode existir. O que essa sociedade traz de novo, e que lhe é peculiar, é a conversão em trabalho abstrato de toda a transformação dos elementos naturais que se volta para a produção de objetos.

Na produção capitalista, o principal objetivo não é apenas produção de mercadoria. O capitalista, ao contratar os serviços do trabalhador, tem em vista que o mesmo produza valores de uso, produtos que sirvam para satisfazer as diversas necessidades produzidas pelos sujeitos. Mas, na verdade, o que interessa prioritária e imediatamente ao capitalista não é o valor de uso e sim o que este valor, ao ser levado ao mercado na forma de uma mercadoria que satisfaça necessidades do "estômago ou da fantasia", representa como valor de troca.

O valor de troca se sobrepõe, no contexto da produção capitalista, ao valor de uso. Este último existe enquanto "substrato material" daquele. Marx (1983, p. 155) informa que 


\section{ADVistg all pavtg}

\} O TRABALHO IMPRODUTIVO E SUAS CONFIGURAÇÕES - BIZERRA, F. A. ; GOIS, J. C. S. ; PINHEIRO, M. A. \}

DOI: $10.12957 /$ REP.2016.25391

O produto - a propriedade do capitalista - é um valor de uso, fio, botas etc. Mas, embora as botas, por exemplo, constituam de certo modo a base do progresso social e nosso capitalista seja um decidido progressista, não fabrica as botas por causa delas mesmas. O valor de uso não é, de modo algum, a coisa qu'on aime pour luimêm ${ }^{1}$. Produz-se aqui valores de uso somente porque e na medida em que sejam substrato material, portadores do valor de troca.

Interessam ao capitalista duas coisas:

Primeiro, ele quer produzir um valor de uso que tenha um valor de troca, um artigo destinado à venda, uma mercadoria. Segundo, ele quer produzir uma mercadoria cujo valor seja mais alto que a soma dos valores das mercadorias exigidas para produzi-las, os meios de produção e a força de trabalho, para as quais adiantou seu bom dinheiro no mercado. Quer produzir não só um valor de uso, mas uma mercadoria, não só valor de uso, mas valor e não só valor, mas também mais-valia (MARX, 1983, p.155).

Para produzir mercadorias e delas extrair mais-valia, o capitalista precisa comprar força de trabalho e explorá-la. Um dos pressupostos para que o capital (e, juntamente, o trabalho abstrato) pudesse se generalizar foi a separação entre os produtores e os meios de trabalho, e a consequente mercantilização da força de trabalho.

Tal separação se deu no contexto da "acumulação primitiva do capital" ocorrida entre os séculos XV e XVI. Ela é entendido como "os revolucionamentos que servem de alavanca à classe capitalista em formação; sobretudo, porém, todos os momentos em que grandes massas humanas são arrancadas súbita e violentamente de seus meios de subsistência e lançadas no mercado de trabalho". (MARX, 1988, p. 253). Ocorre aí, sob o protetorado do Estado Absolutista, a expropriação do campesinato das áreas agrícolas, que agora são destinadas à criação de ovelhas que fornecem a lã para as manufaturas nascentes; a expansão das relações mercantis; o disciplinamento violento da massa de trabalhadores a serem enquadrados no sistema de trabalho assalariado que se instaurava; a formação dos grandes monopólios comerciais; o deslocamento da rota comercial para o Atlântico, principalmente para a América; e a descoberta de novas fontes de riquezas antes inexploradas.

O desenvolvimento da produção capitalista demanda, já nos seus primórdios, possuidores de dinheiro, meios de produção e meios de subsistência, que se submetam a comprar, por um determinado tempo, força de trabalho alheia. Para isso, é preciso que haja trabalhadores "livres", alijados dos seus meios de subsistência necessários à reprodução autônoma de suas vidas, que são condicionados a vender sua própria força de trabalho em

${ }^{1}$ Que se ama por si mesma [Nota dos tradutores]. 


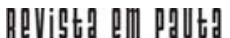

\} O TRABALHO IMPRODUTIVO E SUAS CONFIGURAÇÕES - BIZERRA, F. A. ; GOIS, J. C. S. ; PINHEIRO, M. A.

DOI: 10.12957/REP.2016.25391

troca de um salário. Isto é, tornam-se mercadorias fundamentais para a produção capitalista.

Na sociedade em que a riqueza aparece como uma "imensa coleção de mercadorias", as operações de compra e venda não se voltam apenas para objetos. Tudo é objeto de compra e venda, tudo passa a se constituir em mercadoria, inclusive a força de trabalho que é fundamental para a produção da riqueza sob a base da propriedade privada moderna. Marx (1983) enfatiza que a relação de um indivíduo com os demais dar-seá tendo como mediação a mercadoria. E aqui vem à tona uma inversão inerente à própria lógica do capital: uma relação social assume a "forma fantasmagórica de uma relação entre coisas"; desse modo, os homens são reduzidos à condição de proprietários (seja de capital ou de força de trabaIho), cabendo tão somente converterem-se em "guardiões da mercadoria".

O sistema de controle do capital funda-se na exploração exacerbada da força de trabalho e na alienação do trabalhador mediante o que é produzido, porquanto a produção volta-se, prioritariamente, não para o atendimento das necessidades de reprodução dos indivíduos, mas para os trâmites do mercado. Desse modo, gera mais-valia, produção e apropriação do valor excedentário, garantindo continuamente sua acumulação. Nele, a constante obtenção do trabalho excedente é condição sine qua non para sua reprodução. É um sistema social que se ergue sob os pilares de formas de controle que subordinam, objetiva e subjetivamente, a força de trabalho às suas determinações reprodutivas. Por essas razões, "não se pode imaginar um sistema de controle mais inexoravelmente absorvente - e, neste importante sentido, 'totalitário' do que o sistema do capital globalmente dominante" (MÉSZÁROS, 2011, p. 96), haja vista que sua dominância "totalitária" no reino material e nas demais esferas da vida social é inegável.

O trabalho abstrato, enquanto categoria da produção tipicamente capitalista, tem por finalidade - ao subordinar o valor de uso ao valor de troca - atender às irreprimíveis necessidades de reprodução do capital. Faz isso mediante a constante e crescente produção de mais-valia, pois esta é a propriedade que adquire o trabalho quando destinado à produção de mercadorias. Essa forma de trabalho aparece como sendo produtivo ou improdutivo. É preciso enfatizar que, sob a égide do capital, ele pode ser ou não produtor de mais-valia, pois

Uma parte do trabalho abstrato produz a mais-valia, uma outra parte realiza a transformação dessa mais-valia em dinheiro (mediação imprescindível para que possa retornar à produção como capital) e, uma terceira, como os funcionários públicos, apenas prestam serviços imprescindíveis (com as devidas mediações) à dominação de classe e, portanto, à continuidade da valorização do capital. (LESSA, 2008, p. 09). 


\section{ADVistg all pavtg}

\} O TRABALHO IMPRODUTIVO E SUAS CONFIGURAÇÕES - BIZERRA, F. A. ; GOIS, J. C. S. ; PINHEIRO, M. A. \}

DOI: $10.12957 /$ REP.2016.25391

$\mathrm{Na}$ forma peculiar e socialmente determinada do processo de trabalho capitalista, em que o acúmulo cada vez mais crescente de riqueza, diante da necessidade de manutenção da lucratividade, é um imperativo sistêmico, nomeia-se trabalho produtivo aquele que necessariamente produz mais-valia. Essa qualidade o diferencia por inteiro do processo de trabalho em geral, cujo trabalho produtivo é, como já demonstrado no início desse item, aquele que se realiza num produto.

A respeito dessa diferenciação, Marx (2010, p. 109 - grifos no original) nos diz que:

Do ponto de vista do processo de trabalho em geral, apresentava-se como produtivo aquele trabalho que se realizava num produto, mais concretamente numa mercadoria. Do ponto de vista do processo capitalista de produção, junta-se uma determinação mais precisa: é produtivo aquele trabalho que valoriza diretamente o capital, o que produz mais-valia, ou seja, que se realiza - sem equivalente para o operário, para o executante - numa mais-valia.

A produtividade do processo de trabalho, em qualquer forma de sociabilidade, reside na capacidade de gerar um produto que tenha, diante das diversas necessidades produzidas pelos homens, um valor de uso. Entretanto, "o processo capitalista de produção não é meramente produção de mercadorias. É um processo que absorve trabalho não pago, que transforma os meios de produção em meios para sugar trabalho não pago" (MARX, 2010 p. 115). Além de produzir uma mercadoria, sob todas as circunstâncias, ele tem que valorizar o capital e, para isso, é imprescindível gerar mais-valia. Vistas as coisas nesse nível,

Trabalho produtivo não é senão expressão concisa que designa a relação no seu conjunto e o modo pelo qual se apresentam a força de trabalho e o trabalho no processo capitalista de produção. Por conseguinte, se falamos de trabalho produtivo, falamos, pois, de trabalho socialmente determinado, de trabalho que implica relação nitidamente determinada entre o comprador e o vendedor de trabalho. $\mathrm{O}$ trabalho produtivo troca-se diretamente por dinheiro enquanto capital, isto é, por dinheiro que em si é capital, que está destinado a funcionar como capital, e que como capital se contrapõe à capacidade de trabalho. (MARX, 2010, p. 114).

Claro está que, além de o trabalhador produzir uma mercadoria que tem um valor de uso, ele também gera novo valor quantificável e sempre expansível, através da venda da sua força de trabalho, que fica à disposição dos capitalistas para ser explorada conforme seus objetivos. Ou seja, acrescenta mais valor do que aquele empregado inicialmente para custeálo, produzindo mais-valia e, por essa via, autovalorizando o capital e alimentando sua lógica internamente movida pela acumulação. De fato, é signi- 


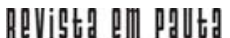

\} O TRABALHO IMPRODUTIVO E SUAS CONFIGURAÇÕES - BIZERRA, F. A. ; GOIS, J. C. S. ; PINHEIRO, M. A.

DOI: $10.12957 /$ REP.2016.25391

ficativo, quanto a isso, o fato de que "o que constitui o valor de uso específico do trabalho produtivo para o capital [...] [é] o seu caráter de elemento criador de valor de troca (mais-valia)" (MARX, 2010, p. 114-115).

Nesta referência analítica, o trabalho produtivo é aquele que produz um excedente para o capitalista e ainda é fonte de remuneração/reposição do capital variável (força de trabalho). Não basta, assim, que o trabaIhador produza para si ou apenas mercadorias vendáveis que tenham utilidade na vida de alguém ao suprir uma dada necessidade; não basta que o trabalhador reponha, atualize somente o valor monetário investido pelo capitalista empregador. O trabalhador deve produzir algo a mais: o lucro a ser convertido em capital.

Outro aspecto deve ser explicitado a fim de se evitarem conclusões equívocas que estão aquém de explicar a realidade: não há identidade entre trabalho produtivo e assalariamento. Não é o fato de ser um assalariado que determina a condição de ser um trabalhador produtivo, pois todo trabaIhador produtivo é assalariado, mas nem todo trabalhador assalariado é produtivo. Como já argumentamos, o trabalhador produtivo, além de assalariado, cumpre a função socialmente determinada de produzir mais-valia. Para Marx (2010, p. 111), quando se compra o trabalho com a finalidade específica de consumi-lo como serviço, pelo seu valor de uso, "não para colocar como fator vivo no lugar do valor do capital variável e o incorporar no processo capitalista de produção, o trabalho não é produtivo". Nesta condição, tal trabalho, ao não gerar a mais-valia que nutre os capitalistas, é, nos termos categóricos do autor, "consumido improdutivamente".

Quanto ao trabalho improdutivo, objeto de reflexão neste estudo, importa salientar que, apesar de não produzir mais-valia, ele não pode ser conceituado como costumeiramente é, ou seja, sem utilidade social. Pelo contrário, ele exerce, à proporção que o capital domina toda a produção de mercadorias desenvolvendo a produtividade do trabalho, uma funcionalidade ao pleno desenvolvimento do capitalismo em suas fases históricas distintas.

Marx (2010, p. 118) define que "serviço não é em geral mais do que uma expressão para o valor de uso particular do trabalho, na medida em que este não é útil como coisa mas como atividade". A atividade de serviços, geralmente, o que não quer dizer sempre ${ }^{2}$, não cria valores de uso que se materializam em um objeto, tendo sua utilidade apenas como atividade.

No caso dos serviços improdutivos, eles são utilizados como valor de uso. Não criam diretamente valor, mas são essenciais, a seu modo, para a manutenção do sistema sociorreprodutivo do capital. No entanto, serviços de conteúdo idêntico também podem, em situações precisas, constituíremse como atividade produtiva. Um exemplo, dentre outros tantos, é escla-

${ }^{2}$ Mais detalhes sobre essa questão, ver: Dal Rosso (2014). 


\section{ADVistg all pavtg}

\} O TRABALHO IMPRODUTIVO E SUAS CONFIGURAÇÕES - BIZERRA, F. A. ; GOIS, J. C. S. ; PINHEIRO, M. A. \}

DOI: $10.12957 /$ REP.2016.25391

recedor: um cozinheiro pode ser um trabalhador produtivo se trabalha em um restaurante, convertendo seu trabalho em meio para o processo de valorização do capital do dono do estabelecimento. Mas o mesmo cozinheiro pode, ainda, ser trabalhador improdutivo se prestar serviços domésticos, porque aí seu trabalho é comprado como valor de uso para ser apenas consumido imediatamente por quem o contratou.

O trabalho prestado através dos serviços será improdutivo quando comprado com a renda do consumidor, não vindo ao caso se este serviço se materializa em uma coisa ou se desaparece ao final de sua execução. Quando comprados para o consumo, em decorrência de seu valor de uso, os serviços não se convertem em fator do capital. Por isso, são considerados como improdutivos. Atesta Tavares (2004, p. 154) que os trabalhadores improdutivos são assalariados regulados pelas leis do salário, que vendem sua força de trabalho para que seja consumida com uma utilidade específica, e seu salário será trocado por renda - o dinheiro passa de uma pessoa para outra. Já o dos trabalhadores produtivos troca-se por capital, ainda que ambos coexistam e estejam organizados sob o modo de produção capitalista, baseados numa necessária relação de assalariamento.

Diferenças consideradas, há, como observa Dias (2006), duas semelhanças entre o trabalhador produtivo e o improdutivo. A primeira diz respeito ao fato de a força de trabalho de ambos serem uma mercadoria vendida ao capitalista por um determinado valor, que é o salário. A segunda semelhança reside no valor da força de trabalho, tanto de um quanto do outro, que é determinado de modo análogo: pelo que custa para sustentálo, pelo que o trabalhador necessita para reproduzir a sua força de trabalho.

Para tudo isso ter se tornado possível foi preciso que houvesse a consolidação da divisão social do trabalho, culminada com a separação e oposição entre o trabalho manual e o trabalho intelectual que, no capitalismo, não serão mais desempenhados pelo mesmo trabalhador. De um lado, tem-se trabalhadores que apenas executam o trabalho - troca orgânica do homem com a natureza donde se produz a riqueza material; de outro, trabalhadores que não produzem mais-valia ao atuarem na gerência, na supervisão e no planejamento, por exemplo. Estes últimos, situados no universo do trabalho improdutivo par excellence, passam "a ser a direção e o controle que se impõe do exterior do trabalho sobre os trabalhadores" (LESSA, 2011, p. 156), fundamentais para a extração da mais-valia.

\section{O trabalho improdutivo na vigência dos "anos dourados"}

Sabe-se que no contexto histórico dos "anos dourados", que se estende da década de 1940 aos finais dos anos 1960, tem-se o aumento da produção industrial na Finlândia, na Espanha, no Japão, na França, na Itália e nos países agrários que ganharam expressivos setores industriais; as 


\section{ReVistg all pautg}

\} O TRABALHO IMPRODUTIVO E SUAS CONFIGURAÇÕES - BIZERRA, F. A. ; GOIS, J. C. S. ; PINHEIRO, M. A. DOI: $10.12957 / R E P .2016 .25391$

mobilizações anticolonialistas, como no caso de Cuba, China e de algumas nações do território africano; a direção militar, política e econômica do sistema imperialista, que anteriormente estava concentrada na Europa e deslocou-se para os Estados Unidos; a exportação de capitais, que antes era conduzida dos países centrais aos periféricos, e a partir de então passa a se estabelecer entre os próprios países centrais; o aumento inflacionário em proporções permanentes; consolida-se a dominação dos meios de circulação de ideias do grande capital (imprensa, rádio, televisão), possíveis graças às Tecnologias da Informação (TI); e cresce a prática do sistema de vendas a crédito ao consumidor.

Ademais, do ponto de vista da organização da produção, esses anos foram marcados pelo padrão taylorista/fordista, que se associou a um novo regime de regulação estatal compatível com a dominação das organizações monopólicas. Consolidou-se, em áreas geopoliticamente identificáveis, o modelo de Estado de matriz keynesiana, demarcando a resposta do capital à eclosão da crise de 1929 e às problemáticas geradas pelo estalar da Segunda Guerra Mundial. Através deles, o sistema capitalista vivenciou três décadas marcadas pela expansão acelerada da acumulação, associada, nesse mesmo processo, a períodos curtos de contração da produção. Foi possível deslocar temporariamente, haja vista que o capital não se coaduna com nenhuma estratégia de controle, contradições intrínsecas ao seu sistema que àquela conjuntura se apresentavam enquanto entraves à expansão capitalista.

Por certo que, no movimento de organização monopolística da indústria moderna, entre fins do século XIX e início do século XX, a gerência científica - mecanismo auxiliar fundamental ao exercício do controle do processo de trabalho capitalista - adquire uma significação inequívoca frente aos problemas administrativos daí erigidos, Taylor, a partir dos Princípios de administração científica, consolidou esforços no sentido de aplicar os métodos da ciência às questões relacionadas ao trabalho nas empresas que rapidamente se expandiam.

Taylor (2008) define que o objetivo da administração "deve ser o de assegurar o máximo de prosperidade ao patrão e, ao mesmo tempo, o máximo de prosperidade ao empregado". O aumento da produção representaria "prosperidade" para os principais sujeitos do processo: empregado e empregador. A administração científica pressupõe que ambos têm os mesmos interesses: "de que a prosperidade do empregador não pode existir se não for acompanhada da prosperidade do empregado, e vice-versa". Sendo assim, como afirma Taylor (2008, p. 24), é preciso "dar ao trabalhador o que ele mais deseja - altos salários - e ao empregador também o que ele realmente almeja - baixo custo de produção".

Obter a prosperidade do empregado e do patrão significa, segundo Taylor (2008, p. 26), que "o trabalho da empresa [deve ser] realizado com o menor gasto de esforço humano, combinado com o menor gasto das 


\section{ADVistg all pavtg}

\} O TRABALHO IMPRODUTIVO E SUAS CONFIGURAÇÕES - BIZERRA, F. A. ; GOIS, J. C. S. ; PINHEIRO, M. A. \}

DOI: $10.12957 /$ REP.2016.25391

matérias-primas, com a menor inversão de capital em instalações de máquinas, em edifícios, etc.". E acrescenta: "[...] a maior prosperidade decorre da maior produção possível dos homens e máquinas do estabelecimento, isto é, quando cada homem e cada máquina oferecem o melhor rendimento possível". Tem-se a necessidade de economizar, ao máximo, os gastos totais necessários para a realização da produção. É preciso que haja aumento da capacidade produtiva do trabalho e a baixa do preço de custo, o que gerará uma produtividade mais lucrativa para os capitalistas. É preciso, também e ainda, que se aperfeiçoem os métodos de racionalização da produção, de maneira a adequá-los aos imperativos estruturais do modo de controle do capital para que se possa, nessa perspectiva, executar em ritmo mais rápido e com maior eficiência os tipos mais elevados de trabalho.

De acordo com Taylor (2008, p. 29), há uma tendência de os trabalhadores, no espaço produtivo, fazerem "cera", isto é, utilizarem métodos que diminuem suas possibilidades de produção, o que acarreta, inevitavelmente, em prejuízo para os capitalistas. Intentando atacar as estratégias dos trabalhadores contra a disciplina de trabalho imposta pelo capital, Taylor (2008, p. 27) constata que a eliminação do hábito de fazer "cera" "advirá, em média, aumento de cerca do dobro da produção de cada homem e de cada máquina". Busca-se, então, remover a "cera" e o "trabalho retardado", fazendo com que os trabalhadores operem suas atividades do "melhor modo e mais rapidamente possível" para que decresça o custo da produção e amplie significativamente a produção da mais-valia. Como suporte, eles recebem a "cooperação" da gerência científica no que diz respeito ao disciplinamento necessário.

A aplicação dos métodos científicos ao processo de trabalho visava a economia de tempo e o consequente acréscimo de rendimento do trabalho obtido "pela eliminação de movimentos desnecessários e [pela] substituição de movimentos lentos e ineficientes por movimentos rápidos em todos os ofícios" (TAYLOR, 2008, p. 33). A partir do estudo "do tempo e dos movimentos", procurou-se o método mais rápido e os instrumentos que melhor se adequavam, nos parâmetros do capital, à potencialização da extração da mais-valia. Aprimoram-se as estratégias que possibilitam a realização do trabalho em conformidade com as "leis científicas", que demarcam a melhor divisão de responsabilidades entre a direção e os setores de chefia, responsáveis pelo planejamento e pela organização produtiva, e o trabalhador que, privado das suas funções de controle, apenas operacionaliza a produção.

A ciência de Taylor reafirma e aperfeiçoa, no estágio monopolista do capitalismo, a clássica oposição estabelecida entre trabalho manual e trabalho intelectual. Defende que a administração deve realizar o planejamento e executar muitas das atividades que até então haviam sido encarregadas aos operários. Dadas as condições estruturais de hierarquia estabelecidas na fábrica, a administração se encarrega das atribuições para as 
quais está "mais bem capacitada", cristalizando as funções de planejar, gerir, supervisionar e controlar completamente o processo de trabalho. Daí o porquê de quase todos os atos dos trabalhadores serem precedidos de atividades preparatórias orquestradas pela direção.

Não é de se estranhar, a esse respeito, que, além de perder o controle sobre os instrumentos de produção, os trabalhadores acabam por perder o controle tanto do trabalho quanto do modo e ritmo da execução. É tão assim que "este controle pertence agora aqueles que podem 'arcar' com o estudo dele a fim de conhecê-lo melhor do que os próprios trabalhadores conhecem sua atividade viva" (BRAVERMAN, 1981, p. 106). Com efeito,

Tanto a fim de assegurar o controle pela gerência como baratear o trabalhador, concepção e execução devem tornar-se esferas separadas do trabalho, e para esse fim o estudo dos processos do trabalho devem reservar-se a gerência e obstado aos trabalhadores, a quem seus resultados são comunicados apenas sob a forma de funções simplificadas, orientadas por instruções simplificadas o que e seu dever seguir sem pensar e sem compreender os raciocínios técnicos ou dados subjacentes. (BRAVERMAN, 1981, p. 107).

Há que se considerar que, desse modo, inicia-se a ampliação do trabalho improdutivo, materializado nas funções da gerência científica e de controle sobre os trabalhadores assalariados que executam as atividades manuais na esfera da produção. Logo, emerge uma gama de profissões ${ }^{3}$ que participam do conjunto de atividades improdutivas na esfera industrial e que se inserem na produção, personificando o capital, para realizar atividades que exigem qualificação técnica e científica. Isso, a nosso ver, é decorrente de duas principais situações: 1) a necessidade do controle e de profissionais que planejem o processo de produção e 2) o próprio aumento da produtividade, visando sempre à maximização dos lucros, que torna ainda mais imprescindível sua presença.

A separação entre os que planejam e, por sua vez, os que executam marca a divisão do trabalho entre diferentes lugares e grupos de trabalhadores. Por isso, a gerência científica, ao propor a cisão entre concepção e execução, moderniza a divisão entre o trabalho manual e o intelectual, vigorando a tendência à alienação do trabalho presente na dissociação e oposição entre a mão e o cérebro. Tal divisão aprofunda-se quando o fator subjetivo do processo de trabalho é tomado do trabalhador e incorporado na e pela gerência.

O fordismo, de modo similar, consiste numa organização do trabalho rígida, simplificada e uniformizada, sendo diretamente funcional à

\footnotetext{
${ }^{3}$ A título de exemplo, Braverman (1981, p. 118) demonstra que "a profissão de engenheiro é um fato relativamente recente. Antes dele, as funções conceptuais e de projeto eram de competência do profissional do ofício, do mesmo modo como as funções de estimular as artes industriais mediante inovação".
} 


\section{ADVistg all pavtg}

\} O TRABALHO IMPRODUTIVO E SUAS CONFIGURAÇÕES - BIZERRA, F. A. ; GOIS, J. C. S. ; PINHEIRO, M. A. \}

DOI: $10.12957 /$ REP.2016.25391

reprodução do capital na fase do monopolismo. Segundo Harvey (1998, p. 121), o que havia de especial em Henry Ford, principal percursor do fordismo - e que, em última instância, o distingue do taylorismo - "era a sua visão, seu reconhecimento explícito de que produção em massa significava consumo em massa", pois apenas esse tipo de produção diminuiria os custos operacionais da produção e, consequentemente, o preço em que o carro seria comercializado. Através de uma produção interiorizada ${ }^{4}$ na própria indústria, Ford busca estabelecer um novo sistema de reprodução da força de trabalho consoante a política de gerência e controle do trabalho tayloriana.

Uma das características do padrão produtivo fordista é o parcelamento das tarefas. Argumenta Gounet (1999) que, "em vez de fazer um veículo inteiro, um operário faz apenas um número limitado de gestos, sempre os mesmos, repetidos ao infinito durante sua jornada de trabalho". Observa-se que o fordismo fragmenta o trabalho em suas partes mais essenciais, decompondo, em seu grau máximo, as tarefas realizadas por cada trabalhador de forma parcelada. Limita sua atividade a movimentos repetitivos cuja somatória resultava na produção do veículo completo. É assim que "o parcelamento significa que o trabalhador não precisa mais ser [como antes] um artesão especialista em mecânica" (GOUNET, 1999, p. 19).

Inevitavelmente, acontece, mediante isso, a desqualificação dos operários. Estes perdem a destreza no trabalho - anteriormente expressa na troca de operações, de ferramentas e, ainda, nos deslocamentos dentro do espaço fabril -, reafirmando sua condição imposta desde a instauração da grande indústria moderna de ser apenas um apêndice da máquina.

Pinto (2010, p. 38) chama atenção para o fato de que, nas condições simplificadas de trabalho impostas pelo fordismo, "a intervenção criativa dos trabalhadores nesse processo é praticamente nula, tal como a possibilidade de conceber o processo produtivo como um todo, pois cada qual é fixado num mesmo ponto da produção o tempo inteiro", recebendo as atividades que são aprioristicamente definidas pelos centros de gerenciamento da produção.

Paralela à fragmentação das tarefas, segue-se a criação da linha de montagem que percorre todas as fases da produção, cuja principal função é interligar os diversos trabalhos sucessivos realizados pelos operários.

Uma esteira rolante desfila, permitindo aos operários, colocados um ao lado do outro, realizar as operações que Ihes cabem. Além de ligar os trabalhos individuais sucessivos, a linha fixa uma cadência regular de trabalho, controlável pela direção da empresa. Permite uma produção fluida, limitando ao máximo os estoques entre operações. (GOUNET, 1999, p. 19).

\footnotetext{
${ }^{4}$ A produção fordista desenvolve-se internamente na fábrica, "recorrendo-se apenas de maneira secundária ao fornecimento externo, ao setor de autopeças" (ANTUNES, 2009, p. 39).
} 
O modelo apoia-se ainda na padronização das peças, produzindo grandes quantidades de produtos com pouquíssimos graus de diferenciação e na automatização das fábricas. Este processo dotava o capital de maior intensidade na extração do sobretrabalho a partir de uma produção mais homogeneizada e enormemente verticalizada, controlada "de cima a baixo". Ora, ao certo, tal processo permitia a intensificação do trabalho humano desenvolvido em limites cada vez mais estreitos de tempo e possibilitava elevadíssimas taxas de lucratividade ao sistema do capital naquele contexto particular de monopolização capitalista.

As transformações operadas na produção, propiciadas pelas inovações tecnológicas e pela combinação da produção em série fordista com o cronômetro taylorista, apresentaram resultados extraordinários que conferiram um contorno diferenciado à expansão capitalista no século XX, nos Estados Unidos e em alguns países europeus. No campo das forças produtivas, tem-se um desenvolvimento acelerado correspondente às necessidades expansivas do capital. Pode-se afirmar que isso é possível porque os sistemas organizacionais fordista e taylorista acentuam a clivagem socioeconômica inaugurada pelo sistema do capital: a radical separação do produtor dos meios de produção e, decorrentemente, a concentração desses meios, sob a forma de monopólios, nas mãos de uma só classe social - a burguesia.

Das fábricas aos escritórios, o método Ford generaliza-se na sociedade produzindo novos métodos de trabalho e um tipo de operário com um modo específico de viver. Além do controle estabelecido nas relações intrafabris, que vão desde a disciplina laborativa infinitamente repetitiva, até a vigilância e a pressão dos inspetores, agora é necessário exercer também o controle sobre as questões relacionadas à vida privada dos trabalhadores; em geral, até as questões familiares e da probidade moral. De modo peculiar, o fordismo, conjugado ao taylorismo, penetra na sociedade como um sistema de reprodução da força de trabalho. Assim, provoca mudanças bruscas nas formas de vida dos sujeitos, de maneira a mantê-los sob a disciplina de trabalho necessária para produzir o acervo de mercadorias padronizadas que aumentou significativamente, à época, a produtividade dos capitalistas.

Por quem era ditada a disciplina imposta aos produtores diretos através da gerência taylorista? Desde que se instaura a moderna divisão social do trabalho, incubem-se dessa tarefa os trabalhadores, técnicos, inseridos nas indústrias que exercem, no âmbito da gerência, os papéis de planificação e organização das etapas laborativas - concentrados nos departamentos funcionais de "planejamento, organização, pesquisa e desenvolvimento; planejamento; controle da produção; inspeção ou controle da qualidade; apuração de custos de fabricação [...]" (BRAVERMAN, 1981, p. 223) - e, ao mesmo tempo, uma função ideológica.

Nesta última, aqueles reproduziram a estrutura hierárquica e fragmentada da empresa, que mantém inabalável as condições para que os 


\title{
ADVistg all pavtg
}

\} O TRABALHO IMPRODUTIVO E SUAS CONFIGURAÇÕES - BIZERRA, F. A. ; GOIS, J. C. S. ; PINHEIRO, M. A. \}

DOI: $10.12957 /$ REP.2016.25391

capitalistas exerçam a dominação. Além disso, perpetuaram relações de mando/submissão, o que justifica, já nesse momento, a presença do trabalho improdutivo para atuar no controle dos trabalhadores.

\begin{abstract}
É por isso que todos os que, acobertados pela competência técnica, são chamados a supervisionar o desenvolvimento da produção, trabalham de fato para a perpetuação da divisão hierárquica do trabalho e das relações de produção capitalistas. Isso é válido para os técnicos subalternos (cronometristas, verificadores, etc.) como para os engenheiros, técnicos superiores e outros dirigentes investidos de funções de comando e de controle. Seu papel, nas indústrias de mão-deobra, é fazer com que mantenha a subordinação do trabalho vivo aos processos mecânicos (trabalho morto) e portanto ao capital. São eles aí os únicos detentores da qualificação técnica e intelectual que o processo de trabalho exige. Monopolizam essa qualificação e, assim, proíbem-na aos operários. São portanto os agentes da desqualificação e da opressão do trabalho manual reduzido a ser apenas manual. Representam aos olhos do operário o conjunto de conhecimentos e de saber técnicos dos quais ele esta privado, a separação entre o trabalho intelectual e manual, entre concepção e execução. Gozam de importantes privilégios financeiros, sociais e culturais. São o inimigo mais próximo do operário. (GORZ, 1996, p. 235-236 - grifos no original).
\end{abstract}

Face às relações sociais capitalistas marcadas pelos antagonismos de classe, "[...] a organização hierárquica e o controle do trabalho aparecem sempre para o capital como a condição de toda produção e como um fim em si" (GORZ, 1996, p. 235).

Verifica-se, contudo, que as formas de controle da força de trabalho na produção capitalista fordista não se restringiram ao despotismo ilimitado da burguesia, como em momentos anteriores. Constata Gramsci (2001, p. 275) que a adaptação ${ }^{5}$ aos novos métodos de produção e de trabalho não pode se dar unicamente através da coação social. Por essa razão, "a coerção deve ser sabiamente combinada com a persuasão e o consenso, e isto pode ser obtido [...] por meio de uma maior retribuição, que permita um determinado padrão de vida, capaz de manter e reintegrar as forças desgastadas pelo novo tipo de esforço". Aumentam-se os salários através do sistema remuneratório de gratificações e concedem-se aos trabalhadores que mantêm vínculo empregatício formal, através do Estado, benefícios e direitos sociais por um tempo limitado, de modo a manter sua eficiência física e abrir a possibilidade de realizar o padrão de vida correspondente à forma de produção e de trabalho.

\footnotetext{
${ }^{5}$ Reconhece-se que essa adaptação não se deu sem que houvesse conflitos. Os trabalhadores expuseram sua insatisfação em relação ao que lhes era imposto, contestando, principalmente via centrais sindicais, a organização do regime de produção intensiva. A esse respeito, ver Antunes (2009).
} 
Tendo em vista a dinâmica de trabalho imposta pelo fordismo, não é de se surpreender que as condições de trabalho são extenuantes devido à disciplina moderna compatível com a administração taylorista e ao ritmo intenso do trabalho. Bosquet (1972, p. 23), analisando a realidade americana dos anos 1960, afirma que nas enormes plantas industriais fordistas materializam-se jornadas de trabalho intensas e infinitamente monótonas que escravizam os trabalhadores ao fazê-los "encaixar 13 pequenos pinos em 13 pequenos furos 60 vezes por hora, oito horas por dia". Buscando evitar o desperdício do tempo de trabalho dos operários que produzem a todo momento, impõem-se paradas autorreguladas e "negociadas", o que torna o trabalho da linha de montagem massificado e embrutecedor.

No referido modelo, destinam-se aos trabalhadores apenas funções auxiliares do sistema de máquinas, a exemplo de encaixar 100 bobinas em 100 carros a cada hora ou até mesmo apertar sete parafusos três vezes por minuto. Os capitalistas conseguem diminuir a diversidade das tarefas e padronizam o trabalho, aumentando significativamente o trabalho excedente gerado na produção homogeneizada. É possível perceber, a partir da descrição do autor, que o trabalhador subsiste aí apenas para produzir, subordinado aos ditames do sistema capitalista, e viver sabendo "aos 22 anos que você ainda estará na linha de montagem aos 60, a menos que morra ou fique aleijado primeiro" (BOSQUET, 1972, p.23).

Acresça-se a isso que, durante a "Era de Ouro", expande-se o setor terciário que heterogeneamente envolve trabalhadores produtivos e improdutivos em atividades financeiras e securitárias, publicitárias, educacionais e nos serviços de hotelaria, de vigilância privada, de infraestrutura, de construção civil etc. Nele, cresceu o contingente de força de trabalho empregada: "de 36,8\% (1910) para 62,1\% (1970), nos Estado Unidos; de 22,2\% (1907) para 41,9\% (1970) na então Alemanha Federal; de 39,7\% (1911) para 50,3\% (1966) na Grã-Bretanha; de 26\% (1911) para 47, 8\% (1970) na França" (NETTO; BRAZ, 2009, p. 201).

Essa hipertrofia expressa um traço próprio do modo de produção capitalista: "a tendência a mercantilizar todas as atividades humanas, submetendo-as à lógica do capital- com efeito, mediante os 'serviços', tomam caráter de mercadoria o trato de educação, da saúde, da cultura, do lazer e os cuidados pessoais (a enfermos, idosos, etc.)" (NETTO; BRAZ, 2009, p. 202). Assim, uma parcela crescente de força de trabalho utilizada nos moldes da forma especificamente capitalista de produzir realiza atividades improdutivas.

\section{O trabalho improdutivo no contexto da produção toyotista}

Se é correto afirmar, no sentido do que foi até aqui argumentado, que as estratégias utilizadas nos "anos dourados" possibilitaram o aumento das taxas de lucro e marcaram uma ampla expansão da economia capitalista, 


\section{ADVistg all pavtg}

\} O TRABALHO IMPRODUTIVO E SUAS CONFIGURAÇÕES - BIZERRA, F. A. ; GOIS, J. C. S. ; PINHEIRO, M. A. \}

DOI: $10.12957 /$ REP.2016.25391

é igualmente verdadeiro, e em contraste, que elas apresentaram, à certa altura, alguns limites. Já no início dos anos de 1970 eclodem claramente seus sinais de esgotamento, de estagnação, não possibilitando as mesmas condições favoráveis à expansão ininterrupta do capital. Não é à toa que, desde essa década até os dias de hoje, desencadeia-se um quadro crítico irreversível e diferenciado.

As crises, entretanto, não são uma novidade do capitalismo contemporâneo. O sistema do capital, principalmente a partir do final do século XIX, experimenta diversas crises que se revelam enquanto "um conjunto de falhas nas relações econômicas e políticas da reprodução capitalista" (SHAIKH, 1983, p. 5). Em contextos históricos específicos, há um excesso de mercadorias que se encontram inviabilizadas do poder de compra por parte dos consumidores. Sem encontrar escoadouro para todos os produtos, abre-se um descompasso entre a produção de mercadorias e a possibilidade de consumo. Como o sistema por si só não gera a procura efetiva para garantir a plena utilização dos recursos materiais e humanos, ele fica vulnerável à suscetibilidade das crises que põem em xeque sua vitalidade.

A dinâmica capitalista revela-se instável: inevitavelmente os preços despencam; aumenta-se o desemprego e a miséria, pois há, sobretudo, a redução da produção que ocasiona a diminuição da força de trabalho empregada; tem-se a destruição não apenas de mercadorias, mas também dos meios de produção e de parte da força de trabalho (aquela que se encontra, a partir desse momento, desempregada). Ainda que a curto prazo, esses aspectos apresentam-se como barreiras para reprodução do capital, ao interromper o movimento de acumulação capitalista, as quais, posteriormente, são contornadas por meio de diversos mecanismos. Neste sentido, são constatáveis, na história do capitalismo, períodos de crises que são imanentes ao seu desenvolvimento e, na análise de Shaikh (1983), expressam, em última instância, as contradições insanáveis da organização produtiva capitalista.

Os traços mais evidentes do refluxo econômico mundial (diferente dos demais, que foram apenas regional ou nacionalmente), inaugurado com a crise do petróleo, traduzem-se, por parte do capital, no esgotamento do padrão taylorista/fordista devido à sua incapacidade de responder, a longo prazo, à retração do consumo; na dissolução do Welfare State, com a consequente diminuição dos gastos públicos destinados à área "social" e transferências de recursos para a rede privada; no crescimento da dívida externa; na relação de dependência econômica dos países periféricos aos países centrais; na hipertrofia do setor financeiro em detrimento do setor produtivo, que não consegue reverter a capacidade ociosa das empresas; no aumento dos preços das matérias-primas e nas altas taxas de juros no mercado. De então pra cá, a fase de expansão econômica antes experimentada pelo sociometabolismo do capital é substituída por uma recessão nunca antes vista. Identifica Mészáros (2011, p. 697 - grifos no original) 


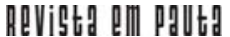

\} O TRABALHO IMPRODUTIVO E SUAS CONFIGURAÇÕES - BIZERRA, F. A. ; GOIS, J. C. S. ; PINHEIRO, M. A.

DOI: $10.12957 / R E P .2016 .25391$

que ela é a "um continuum depressivo, que exibe as características de uma crise cumulativa, endêmica, mais ou menos permanente e crônica, com a perspectiva última de uma crise estrutural cada vez mais profunda e acentuada".

Muito embora se tenha a instalação de uma crise destas proporções, isso não impede que o capital, em face dos seus próprios limites estruturais, continue exercendo a dominação sobre o conjunto da humanidade. Ele continua, apesar de se valer de novos e velhos mecanismos. Visando dar respostas a essa conjuntura, o sistema capitalista iniciou um processo de reorganização econômica, ideológica e, como é de se esperar, também política

[...] cujos contornos mais evidentes foram o advento do neoliberalismo, com a privatização do Estado, a desregulamentação dos direitos do trabalho e a desmontagem do setor produtivo estatal [...]; a isto se seguiu também um intenso processo de reestruturação da produção e do trabalho, com vistas a dotar o capital do instrumento necessário para tentar repor os patamares de expansão anteriores. (ANTUNES, 2009, p. 33 - grifos no original).

Vale dizer que é este último aspecto, bem como sua necessária problematização, que mais diretamente nos interessa. Numa ofensiva contra o trabalho, o capital se vê compelido a encontrar alternativas para a crise em que é absorvido no sentido de reordenar tanto a produção e as formas de acumulação, quanto seu controle sobre a sociedade, trazendo como resultado de suas medidas consequências severas para a classe trabalhadora. Diante dessas circunstâncias, passa-se, então, a substituir o padrão "rígido" por um novo padrão produtivo centrado na "flexibilidade", que responde no âmbito econômico às novas exigências.

A partir daí, confrontando-se com um quadro de agudização das suas contradições imanentes e recorrendo a outro tipo de regime de acumulação, é iniciado um conjunto de transformações no processo produtivo por meio, principalmente, da constituição do avanço tecnológico - microeletrônica, informática e automação, das formas de acumulação "flexíveis" advindas da introdução do modelo toyotista de produção. Consolidado inicialmente no Japão, já nos anos 1950, o modelo "flexível" idealizado por Toyoda Sakichi, Toyoda Kiichirõ e Taiichi Ohno espraia-se por grandes companhias em diversas partes do mundo: da Itália aos Estados Unidos, do Japão à América Latina.

No sistema implantado, a produção é puxada de acordo com o que é posto pela demanda. Desse modo, toda a produção visa atender às demandas individualizadas do mercado e evita, assim, a consequente queda da taxa de lucro. A produção é sempre condicionada pelo consumo, realizando-se em pequena escala e, com isso, reduzindo o tamanho dos lotes. Ocorre a intensificação do ritmo em que é realizado o trabalho, exigindo 


\section{ADVistg all pavtg}

\} O TRABALHO IMPRODUTIVO E SUAS CONFIGURAÇÕES - BIZERRA, F. A. ; GOIS, J. C. S. ; PINHEIRO, M. A. \}

DOI: $10.12957 /$ REP.2016.25391

habilidade e celeridade do trabalhador; a eliminação absoluta dos desperdícios provenientes da superprodução desmedida e da produção de produtos defeituosos; o melhor aproveitamento do tempo através do princípio do just in time (apenas-a-tempo), que nada mais é senão a possibilidade de "adquirir os produtos na hora e na quantidade necessárias" (OHNO, 1997, p. 131); a instalação do sistema de kanban - placa de comando que avisa quando é necessário repor peças; a flexibilização da organização do trabalho e a polivalência do trabalhador, que deixa de ser monofuncional e passa a operar várias máquinas diferentes.

$\mathrm{Na}$ era da acumulação "flexível", marcada principalmente pela produção segmentada, horizontalizada e descentralizada, consolida-se a empresa enxuta que, mesmo dispondo de um menor contingente de força de trabalho, alcança maiores índices de produtividade mediante os métodos de superexploração da força de trabalho.

A flexibilidade nas relações trabalhistas não decorre imediatamente do processo de reestruturação capitalista; ela é anterior a esse processo. O que se apresenta como inovação é a intensificação das formas flexíveis de contratação. A lógica flexibilizadora e seus mecanismos para obtenção de mais-valia impulsionam uma gigante informalização do trabalho, seja produtivo ou improdutivo, cujos nexos inextrincavelmente se articulam com a acumulação do capital. Logo, partes do processo para execução de um produto podem ser realizadas em ambientes externos às fábricas, reeditando, assim, o trabalho domiciliar.

Muitos dos trabalhos realizados em domicílio, na reestruturação capitalista, efetivam a mesma função desempenhada na fábrica, embora com condições e relações de trabalho diferenciadas, pois traduzem uma superexploração do trabalho da mulher, a incorporação do trabalho infantil, a ampliação das jornadas de trabalho, a ausência de proteção social, o aviltamento do trabalho provocado pela figura do intermediário que, por sua vez, assume funções do capital. Ou seja, é o próprio trabalhador explorando outro trabalhador.

Entende-se que o intermediário realiza atividades de natureza improdutiva porque

Ele retira as peças da fábrica, faz a distribuição pelos domicílios, recolhe-as e paga-as semanalmente, encarregando-se de manter a distância necessária entre capital e trabalho. O intermediário entre a empresa e a trabalhadora - grande parte do trabalho domiciliar é realizado por mulheres - controla o uso da matéria-prima exigindo o máximo de economia, e contribui para o aviltamento do salário de quem executa o trabalho. Como um primeiro intermediário pode repassar para um segundo, e este para um terceiro, a cada repasse o pagamento por aquela operação é reduzido. Quanto mais intermediários, menor o salário do trabalhador, pois o rendimento do intermediário é retirado do valor que a empresa paga por cada par de peças trabalhadas. Com isso, vai sendo criada uma cadeia de exploração, na qual um 
trabalhador vai diminuindo a remuneração do outro. (TAVARES, 2004, p. 177).

Um exame cauteloso, à luz da história, revela que as pequenas empresas, a partir da acumulação flexível, foram expandidas e atualizadas para atender às demandas do mercado e às exigências atuais da acumulação capitalista, constituindo-se um dos principais segmentos do setor informal. O trabalho executado na pequena empresa compreende tanto uma dimensão improdutiva, quando vinculado aos serviços (como limpeza e segurança), quanto produtiva, ao se relacionar de modo direto com as indústrias (têxtil, de calçados e confecções). Decididamente, "[...] o incentivo às pequenas empresas tem como fim último deixar a cargo do trabalhador a tarefa de explorar a si e a outrem para o capital" (TAVARES, 2004, p. 186).

Além do trabalho domiciliar e das pequenas empresas, emergem, como alternativa à crise, as chamadas cooperativas, que têm sido empregadas de modo a cumprir funções produtivas e improdutivas ao capital, cujo objetivo é explorar determinada atividade econômica em prol dos seus sócios; "além de ser o de garantir a reprodução dos trabalhadores, é criar um capital social, fruto do trabalho, mas isso nem de longe está orientado à superação do modo de produção capitalista" (TAVARES, 2004, p. 155). Em essência, as cooperativas representam um mecanismo de intensificação da exploração do trabalho, pois quem dirige o trabalho nelas desenvolvido, determinando o que é e como é produzido, e se apropria da produção e da mais-valia produzida, são as empresas capitalistas.

É tão assim que a externalização das atividades laborativas se apresenta no trabalho domiciliar, nas pequenas empresas e nas cooperativas, atribuindo-Ihes características de organização "livre", e os olvida como trabalho subordinado à divisão social do trabalho e aos ditames que regem a produção capitalista. Nessas condições, a finalidade é, em todo caso, negar a produtividade de trabalhos realizados sob a informalidade requerida pelas empresas dos setores produtivos e dos improdutivos, sobretudo, nestes últimos, nas diferentes redes de venda, na tentativa de imprimir mais velocidade ao processo de circulação das mercadorias.

Devido ao desenvolvimento das forças produtivas e aos avanços técnicos e científicos, ocorre, nessa nova dinâmica do capital, uma intensiva incorporação destes à produção, reduzindo, tendencial e parcialmente, a demanda por trabalho vivo. Aprisionada aos nexos e às hierarquias da produção toyotista, a microeletrônica, por exemplo, desempenha um papel central ao explorar a componente intelectual do trabalhador, pois a informática recolhe e guarda os resultados da inteligência prática dos trabalhadores e a automatização aplica esses resultados nas operações realizadas pelas máquinas. Através dela, os conhecimentos técnicos adquiridos pelos trabalhadores também são incorporados no processo de produção e 


\title{
ADVistg all pavtg
}

\} O TRABALHO IMPRODUTIVO E SUAS CONFIGURAÇÕES - BIZERRA, F. A. ; GOIS, J. C. S. ; PINHEIRO, M. A. \}

DOI: $10.12957 /$ REP.2016.25391

os estimulam, principalmente pela propalada "gestão participativa", a dar opiniões a respeito das técnicas produtivas. A própria administração das empresas, exercida por trabalhadores improdutivos, passa a assimilar os conhecimentos técnicos dos trabalhadores incorporando-os à produção para aumentar a eficiência e salvaguardar a produtividade.

O modelo toyotista, além de implicar flexibilidade da produção, acentua a divisão social do trabalho inaugurando um novo patamar de intensificação do ritmo das atividades ao combinar as formas relativa e absoluta de extração da mais-valia. Cabe notar que:

\begin{abstract}
De um lado existem os trabalhadores que sustentam a modalidade de mais-valia relativa inaugurada pelo toyotismo. Caracterizam-se por uma situação profissional estável e por salários bastaste elevados, mas são eles os mais explorados, porque a sua capacidade intelectual está plenamente ao serviço do capital. No outro extremo existem os trabalhadores mais mal pagos, contratados ao dia ou a hora e que alternam o trabalho com períodos de inatividade. Mas como são desprovidos de qualificação e é sobretudo força física que põem ao serviço do patrão, são os menos produtivos e por isso são os menos explorados. Entre estes dois extremos situam-se a hierarquia de qualificações e as múltiplas formas de conjugar o esforço físico e a capacidade intelectual, assim como se situam todas as variantes da precarização e as hierarquias de remunerações e de benefícios. A nova articulação entre mais-valia relativa e mais-valia absoluta, iniciada pelo toyotismo, confere uma ordem a esta multiplicidade e permite dividir a força de trabalho dos nossos dias em grupos relativamente bem caracterizados. (BERNARDO, 2004, p. 136-137).
\end{abstract}

Tais mudanças incidem diretamente na composição da classe trabalhadora, consubstanciando numa própria reestruturação interna através da adoção, aos saltos, de novas formas de contratação, alterações organizacionais na estrutura produtiva que ocasionam instabilidade e precariedade das relações de trabalho, subcontratação, exigências de contenção salarial e ausência de postos de trabalho protegidos e de larga duração. A ameaça real ao desemprego crônico, aliada às estratégias de organização do trabalho e de controle que exploram a componente intelectual do trabalhador, é decisiva para a sua aceitação aos mecanismos de subordinação. Apenas "submetendo a um controle permanente tanto a formação intelectual da força de trabalho como a atividade intelectual dos trabalhadores é que se torna possível desenvolver a componente intelectual do trabalho e apelar para que os trabalhadores participem na gestão" (BERNARDO, 2004, p. 107).

A precarização do trabalho, no mencionado quadro, é a expressão mais significativa da ofensiva do capital sobre o trabalho. Na ótica da ideologia dominante, defendem-se as formas precárias de emprego e o emprego em tempo parcial (que não garantem, ou garantem apenas minimamente, 


\section{hevistg ent paltg}

\} O TRABALHO IMPRODUTIVO E SUAS CONFIGURAÇÕES - BIZERRA, F. A. ; GOIS, J. C. S. ; PINHEIRO, M. A.

DOI: $10.12957 / R E P .2016 .25391$

os direitos sociais) sob a retórica de que a flexibilização e a desregulamentação das relações de trabalho ampliam e expandem as oportunidades no mercado de trabalho. Constata-se, com isso, que o capital exige modificações nas suas condições de acumulação, visando e impulsionando os superlucros. A precarização do trabalho e a informalidade, que garante a tão desejada flexibilidade, atingem tanto os trabalhadores produtivos quanto os improdutivos, e ambos possuem nexos imprescindíveis para a acumulação do capital.

Já foi mencionado, no item anterior, que a hipertrofia do setor de serviços é uma característica que aparece primeiramente na fase dos "anos dourados" do capitalismo; agora, deve-se mencionar que ela ganha outros contornos e destaque na contemporaneidade.

Viu-se que, para Marx (2010), os serviços representam um valor de uso particular do trabalho. Ele considera apenas seu valor útil, numa relação entre o produtor e o consumidor. Essa explicação, realizada quando os serviços correspondiam aos serviços pessoais, é de extrema atualidade, visto que a maioria dos serviços, destacando os voltados para a reprodução da força de trabalho, como os da saúde e educação, conserva a característica de atender a uma necessidade. Sendo assim, infere-se que mesmo os serviços se expandindo e se diversificando seu caráter de atividade que realiza um valor de uso mantém-se.

De posse dessa verificação, é preciso qualificar as atividades realizadas no setor de serviços, tanto no que se refere ao processo de valorização do capital quanto das formas contemporâneas de subordinação hierárquica do trabalho ao capital. Materializados numa etapa de crise capitalista, crescem quantitativamente os serviços que estão ligados ao processo produtivo. Além disso, num cenário de lutas, a incorporação de algumas necessidades de reprodução da força de trabalho determina a progressiva mercantilização, estimulada em grande parte pelo Estado, de serviços sociais que possibilitam, em alguma medida, o controle político, social e ideológico de parte significativa da classe trabalhadora.

Oliveira (1979), analisando esse movimento, destaca que para compreender o papel do setor terciário na divisão social do trabalho em sua versão capitalista, principalmente na fase contemporânea, é preciso apreendê-lo enquanto esfera particular da circulação do capital. Essa divisão do trabalho é marcada por novas condições de acumulação do capital, por mudanças nas esferas da produção, circulação e consumo, e pelo crescimento do trabalho improdutivo que compõe, em larguíssima medida, o setor de serviços. Impõe-se considerar, portanto, que esse setor, resguardadas suas especificidades, é composto pelas atividades relacionadas à circulação, à distribuição e ao consumo, cuja atuação e funcionalidade, a seu tempo, conectam-se diretamente à esfera produtiva.

A expansão dos serviços na esfera da circulação pode ser percebida através do inchaço nos chamados serviços de intermediação 


\section{ADVistg all pavtg}

\} O TRABALHO IMPRODUTIVO E SUAS CONFIGURAÇÕES - BIZERRA, F. A. ; GOIS, J. C. S. ; PINHEIRO, M. A. \}

DOI: $10.12957 /$ REP.2016.25391

financeira, "que compreendem os bancos, as companhias financeiras, as de seguro, enfim, todo o aparato de circulação do capital" (OLIVEIRA, 1979, p. 145). Já devido aos movimentos imanentes de concentração e centralização do capital, observa-se a redução no número de agentes e, em contrapartida, "se amplia o controle do chamado capital financeiro sobre o conjunto da economia, o que responde pela ampliação dos serviços que cuidam exatamente do controle do capital financeiro". Sob a ótica da distribuição e circulação de mercadorias revela-se a funcionalidade dos serviços para a expansão do capital, segundo Oliveira (1979, p. 145-146), "quando se assiste à substituição da cissiparidade dos pequenos estabelecimentos pela concentração nos supermercados, lojas de departamentos etc.".

Além disso, por ser um sistema de inquestionável dominação totalitária que usurpa totalmente o poder de tomada de decisões, o capitalismo requer uma gama de profissões que contribuam para isso. Dessa forma, é compreensível que, "quando as relações técnicas e o chamado avanço tecnológico apontam no sentido da eliminação de funções, ocupações e profissões assiste-se à persistência delas, cumprindo papeis de controle social sobre os trabalhadores da base técnica e produtiva propriamente dita" (OLIVEIRA, 1979, p. 142).

Os centros metropolitanos, atualmente, são compostos por um conjunto de serviços de controle, desde atividades políticas (executivas, legislativas, judiciais), financeiras, de informática, fiscais, até as religiosas. Há, também, outros serviços de controle que se ampliaram desde que se formaram os monopólios. São, como nos diz Singer (1979, p. 135), "os serviços de compras, vendas, 'marketing', finanças, contabilidade etc. É provável que todo o pessoal administrativo e de vendas das indústrias e das explorações agrícolas e extrativas exerçam, na maior parte de seu tempo, funções de controle".

Convivendo ao lado de tais serviços, emergem e se organizam outros serviços cuja função principal é o atendimento de parte das necessidades da população, como cinemas, centros de cultura, escolas e hospitais. Decerto, tanto parte dos serviços de saúde como a escola podem exercer funções de controle social. Para Singer (1979, p. 134-135), "Os serviços escolares e de saúde só têm eficácia enquanto manipuladores e/ou repressores de contradições sociais na medida em que a população os procura para satisfação de suas necessidades".

É inconteste que a ampliação dos serviços, incluindo os serviços sociais, justifica-se pela necessidade absolutamente vital de o capital controlar e amenizar, ainda que temporariamente, os conflitos e problemas sociais decorrentes das iniquidades produzidas pelo próprio sistema e garantir, em certa medida, a reprodução da força de trabalho a ser capitalisticamente explorada. Por esse motivo, a função de controle político-ideológico e econômico sobre a classe trabalhadora, necessária ao domínio de classe e 
posta em prática por seguimentos profissionais, evidencia a natureza improdutiva dessas atividades porque não geram mais-valia e atuam no sentido de garantir o funcionamento adequado do capitalismo.

\section{Considerações finais}

Particularizando a regência e a dinâmica de reprodução do capital na sua busca incessante pelo lucro, vimos que, apesar de haver profissionais não atuantes diretamente na produção, eles são essenciais para a exploração e controle dos demais trabalhadores. Vimos, ademais, que ambos vendem sua força de trabalho em troca de um salário. Braverman (1981, p. 342) diz que, desde a instauração do capitalismo monopolista, em especial, "quase toda a população transformou-se em empregada pelo capital", e as atividades que anteriormente não estavam inseridas na relação capitalista de assalariamento, desse período em diante, passaram a estar. Portanto, a partir das necessidades que fazem do sistema atual um modo de controle singular, demanda-se o trabalho daqueles que transformam a natureza, produzindo o capital, e dos numerosos assalariados que controlam e organizam o trabalho a ser realizado pelos primeiros. Tratam-se, claro está, de dois tipos de trabalhadores distintos, pela função social por eles assumidas, não obstante essenciais à reprodução econômica.

Na dinâmica do século XX, complexifica-se a divisão social do trabalho e a tendência de ampliação do trabalho improdutivo. Na contemporaneidade ocorre, como demonstrado, a expansão dos trabalhos improdutivos que ganharão maior destaque com a flexibilidade do trabalho. Tal expansão é expressa nos processos de terceirização e na informalidade, que engloba um contingente de trabalhadores improdutivos. Nesse contexto, além da exploração física, explora-se a componente intelectual do trabalho. Essa exploração foi possibilitada pelas invenções tecnológicas aplicadas ao processo produtivo, o que acarretou na redução relativa do trabalho vivo. É explicável, portanto, o surgimento de diferentes profissões que auxiliam a reprodução do capital, o redimensionamento da função de controle, a expansão do trabalho improdutivo na fábrica e a hipertrofia/diversificação do chamado setor de serviços, composto em sua maioria por atividades improdutivas.

Em suma, ao contrário de alguns argumentos teóricos apresentados na Introdução, apreende-se com os resultados aqui obtidos que a produção flexível, apesar de promover alterações substantivas no processo de trabalho, propiciadas pelo desenvolvimento tecnológico, não conseguiu e nem conseguirá suplantar a distinção elementar entre trabalho produtivo e trabalho improdutivo. Estas formas de trabalho não se fundiram nem se "imbricaram" de modo a esvaecer suas distinções ontológicas. Há comprovação histórica, por todas as constatações possíveis no decorrer do texto, 


\section{ReVistg all pautg}

\} O TRABALHO IMPRODUTIVO E SUAS CONFIGURAÇÕES - BIZERRA, F. A. ; GOIS, J. C. S. ; PINHEIRO, M. A. \}

DOI: 10.12957/REP.2016.25391

que essa organização do trabalho reafirma tal distinção ao possibilitar que o capital, mesmo diante do quadro de crise, continue explorando intensivamente os diversos segmentos de trabalhadores, produtivos ou não, e situados em setores os mais diferenciados, a fim de superar esse quadro que põe em xeque a viabilidade de sua existência enquanto sistema sociometabólico.

O trabalho improdutivo continua, como sempre, distintamente constituído daquele que produz mais-valia - portanto, produtivo e aprisionado aos grilhões que envolvem a economia no interior da estrutura social que antagoniza capital e trabalho! 
ReVistg all paltg

\} O TRABALHO IMPRODUTIVO E SUAS CONFIGURAÇÕES - BIZERRA, F. A. ; GOIS, J. C. S. ; PINHEIRO, M. A. \}

DOI: $10.12957 / R E P .2016 .25391$

\section{Referências}

ANTUNES, R. Os sentidos do trabalho: ensaio sobre a afirmação e a negação do trabalho. São Paulo: Boitempo. 2009.

BERNARDO, J. Democracia totalitária: teoria e prática da empresa. São Paulo: Cortez. 2004.

BOSQUET, M. The 'Prison Factory'. New Left Review, Londres, n. 73. 1972. BRAVERMAN, H. Trabalho e capital monopolista: a degradação do trabalho no século XX. Rio de Janeiro: LTC. 1981.

DAL ROSSO, S. Teoria do valor e trabalho produtivo no setor de serviços. Caderno CRH, Salvador, v. 27, n. 70, jan./abr. 2014.

DIAS, C. M. N. P. Trabalho produtivo e trabalho improdutivo: de Marx à polêmica marxista (Napoleoni, Rubin e Mandel). Tese (Doutorado da PósGraduação em Serviço Social) -Escola de Serviço Social da Universidade Federal do Rio de Janeiro. 2006.

GORZ, A. Crítica da divisão do trabalho. São Paulo: M. Fontes. 1996.

GOUNET, T. Fordismo e toyotismo na civilização do automóvel. São Paulo: Boitempo Editorial. 1999.

GRAMSCI, A. Caderno 22 (1934): americanismo e fordismo. Cadernos do Cárcere, Rio de Janeiro: Civilização Brasileira, v. 4. 2001.

HARVEY, D. Condição pós-moderna: uma pesquisa sobre as origens da mudança cultural. São Paulo: Edições Loyola. 1998.

KUMAR, K. Da sociedade industrial à pós-moderna: novas teorias sobre o mundo contemporâneo. Rio de Janeiro: Zahar Editor. 2006.

LESSA, S. Marx, Lukács, trabalhadores e proletariado. 2008. Disponível em: <http://www.sergiolessa.com/CapLivro08/mrx_lkcs_classes_2008.pdf>. Acesso em: 12 de jun. 2014.

Cortez. 2011.

. Trabalho e proletariado no capitalismo contemporâneo. São Paulo:

MARX, K. O capital. Vol. I. Tomo I. São Paulo: Nova Cultura. 1983.

. Teorias da mais-valia: história crítica do pensamento econômico. Vol. I. Rio de Janeiro: Bertrand Brasil. 1987.

. O capital. Vol. I. Tomo II. São Paulo: Nova Cultura. 1988.

. Capítulo VI Inédito de O capital. São Paulo: Centauro. 2010.

MÉSZÁROS, I. Para além do capital. São Paulo: Boitempo. 2011.

NAPOLEONI, C. Lições sobre o capítulo sexto (inédito) de Marx. São Paulo: Livraria Ciências Humanas. 1981. 


\section{ApVistg all pavtg}

\} O TRABALHO IMPRODUTIVO E SUAS CONFIGURAÇÕES - BIZERRA, F. A. ; GOIS, J. C. S. ; PINHEIRO, M. A. \}

DOI: $10.12957 /$ REP.2016.25391

NETTO, J. P.; BRAZ, M. Economia política: uma introdução crítica. São Paulo: Cortez. 2009.

OHNO, T. O sistema Toyota de produção: além da produção em larga escala. Porto Alegre: Bookman. 1997.

OLIVEIRA, F. de. O terciário e a divisão social do trabalho. Novos Estudos Cebrap, Rio de Janeiro, n. 24. 1979. Disponível em: <http://www.cebrap .org.br/v1/upload/biblioteca_virtual/o_terciario_e_a_divisao_social.pdf>. Acesso em: 2 de mar. 2015.

PINTO, G. A. A organização do trabalho no século 20: taylorismo, fordismo e toyotismo. São Paulo: Expressão Popular. 2010.

SHAIKH, A. Uma introdução à história das teorias de crise. Ensaios FEE, Porto Alegre, v. 4. 1983.

SINGER, P. I. A economia dos serviços. Novos Estudos Cebrap, Rio de Janeiro, n. 24. 1979. Disponível em: <http://www.cebrap.org.br/v1/upload/biblio teca_virtual/a_economia_dos_servicos.pdf >. Acesso em: 10 de out. 2013.

TAVARES, M. A. Os fios (in)visíveis da produção capitalista: informalidade e precarização do trabalho. São Paulo: Cortez. 2004.

TAYLOR, F. W. Princípios de Administração Científica. São Paulo: Atlas. 2008.

Recebido em 31 de julho de 2015.

Aprovado para publicação em 07 de janeiro de 2016.

DOI: 10.12957/rep.2016.25391

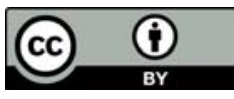

A Revista Em Pauta: Teoria Social e Realidade Contemporânea está licenciada com uma Licença Creative Commons Atribuição 4.0 Internacional. 